\title{
A FERRO E FOGO, HISTÓRIA AMBIENTAL E A GEOGRAFIA BRASILEIRA: UM DIÁLOGO POR INVENTAR*
}

\author{
Christian Brannstrom
}

Texas A\&M University

\section{Resumo}

Neste ensaio, avalio os vinte anos de repercussão do livro A Ferro e Fogo: a história e a devastação da Mata Atlântica brasileira, do historiador brasilianista Warren Dean, na geografia brasileira. Constato que, ao contrário do que aconteceu entre os historiadores, o livro não provocou acalorado debate entre os geógrafos, sobretudo entre os geógrafos humanos. Dentre as razões para isso destaco (1) o número relativamente pequeno de geógrafos históricos, (2) a grande influência de Milton Santos e sua teoria 'desnaturalizadora' do ambiente e (3) o apego dos geógrafos a certos conceitos, sobretudo o de espaço. Houve algum engajamento por parte de geógrafos físicos (lato sensu) e geógrafos humanos menos ortodoxos. Em colaboração com os historiadores, esses pesquisadores testaram, questionaram e aprofundaram algumas das afirmações de Dean, como a homogeneidade vegetacional da Mata Atlântica e o papel das formigas cortadeiras na agricultura colonial. Por fim, sugiro cinco temas trabalhados por Dean que poderiam ser mais explorados pelos geógrafos brasileiros.

Palavras-chave: Warren Dean; A Ferro e Fogo; história ambiental; geografia brasileira.

\begin{abstract}
In this essay, I evaluate the twenty-year impact of the book With Broadax and Firebrand: the destruction of the Brazilian Atlantic Forest, by the Brazilianist historian Warren Dean, on Brazilian geography. I note that, contrary to what happened among historians, the book did not spark such a heated debate among geographers, especially human geographers. Among the reasons for this are (1) the relatively low number of historical geographers, (2) the large influence of Milton Santos and his theory of a 'denaturalized' environment and (3) the attachment by geographers to certain concepts, space above all. There was some engagement with the book by physical geographers (lato sensu) and less orthodox human geographers. In collaboration with historians, these scholars tested, questioned and deepened some of Dean's claims, such as the vegetation homogeneity of the Atlantic Forest and the role of leaf-cutting ants in colonial agriculture. Finally, I suggest five themes partly developed by Dean that could be better explored by Brazilian geographers.
\end{abstract}

Key words: Warren Dean; With Broadax and Firebrand; environmental history; Brazilian geography.

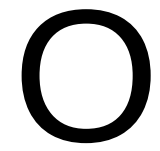

ano de 2016 marca o aniversário de 20 anos de publicação da tradução para o português de With Broadax and Firebrand: the Destruction of the Brazilian Atlantic Forest (traduzido como "A Ferro e Fogo: a História e a Devastação da Mata Atlântica brasileira"), de Warren Dean, um dos mais influentes estudiosos norte-americanos do Brasil. O livro detalha os processos de destruição e conservação dos 1,3 milhões de quilômetros quadrados do bioma Mata

\footnotetext{
* Tradução de Diogo de Carvalho Cabral (CGEO/IBGE).
} 
Atlântica. A Ferro e Fogo apareceu num momento-chave, quando o movimento ambiental brasileiro tinha começado a se configurar como uma importante força política, com organizações nãogovernamentais profissionais alcançando estabilidade organizacional e financeira, além de influência político-institucional. Os pesquisadores nacionais, sobretudo na área da história, estavam começando a desenvolver estudos sobre o passado dos ambientes brasileiros. Com A Ferro e Fogo, eles passaram a ter uma obra em português, fruto de uma densa e longa pesquisa e que oferecia argumentos que podiam ser averiguados e debatidos; os estudantes tinham uma leitura acessível que os encorajava a releituras e revisões da própria obra, preenchendo lacunas, questionando os argumentos provocativos do seu autor e dialogando com sua linha narrativa geral, qual seja, a de um processo perdulário e irracional de destruição da Mata Atlântica que já estava se repetindo no "imenso vizinho do oeste", a Floresta Amazônica (DEAN, 1996, p. 380).

Mas Warren Dean acabou falecendo antes mesmo que a versão em inglês fosse publicada. Assim, a comunidade acadêmica teve que se engajar num diálogo de mão única com um pesquisador que tinha proferido a "primeira palavra" em muitos temas da história da Mata Atlântica, mas que nunca pode responder às críticas. Enquanto historiadores e cientistas naturais têm citado repetidamente A Ferro e Fogo, dialogando intensamente com o livro, os geógrafos brasileiros permaneceram relativamente silenciosos, com algumas poucas exceções. O vigésimo aniversário da obra parece ser um momento propício para uma reflexão sobre as relações (ou falta de relações) entre ela e a comunidade geográfica. Qual foi o impacto de A Ferro e Fogo na geografia brasileira? Os geógrafos ainda estão debatendo o livro? (Há prospectos favoráveis quanto a isso?) $A$ Ferro e Fogo conseguiu revigorar a geografia histórica? Oportunidades de diálogo foram perdidas? Essas são as questões que procuramos responder nas páginas a seguir.

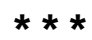

No final de 1993, quando eu - então um estudante de doutorado - planejava fazer trabalhos de campo no Brasil, com especial interesse por erosão do solo, escrevi uma carta para Dean perguntando se ele poderia orientar-me quanto à geografia histórica do estado de São Paulo. Dean respondeu (isto foi antes do correio eletrônico) pedindo que eu telefonasse pela manhã. Quando ele atendeu, eu recordo ouvir música clássica ao fundo, enquanto conversávamos sobre possíveis temas de pesquisa. Dean foi muito gentil e generoso - ele certamente tinha recebido muitos telefonemas como aquele ao longo dos anos - e me disse que sim, que havia de fato enormes voçorocas no estado de São Paulo e que não era difícil encontrá-las. Ele sugeriu algumas leituras, especialmente um artigo (DEAN, 1989a) sobre os aspectos ambientais da lavoura cafeeira em São Paulo (o qual eu tinha negligenciado, por algum motivo), e me desejou tudo de bom. Na época, eu não sabia que Dean havia morado em Assis, São Paulo, entre junho e agosto de 1975 (OLIVEIRA, 2013, pp. 256-7). Nesta cidade, ele deve ter se familiarizado com uma voçoroca conhecida como "buracão", a qual tinha crescido tanto a ponto das autoridades municipais criarem um parque público ao seu redor, instalando uma pista de corrida ladeada por jaboticabeiras que se enchia de crianças vorazes e determinadas durante a época de frutificação (eu descobri isso depois, quando morava em Assis para fazer o trabalho de campo de minha tese, em 1996-97).

Alguns meses depois daquele telefonema, quando eu estava preparando minha primeira vi- 
agem a São Paulo, pensei em telefonar para agradecer Dean por seu aconselhamento, mas, por acaso, acabei encontrando seu obituário no New York Times: ele havia falecido no Chile, asfixiado por um vazamento de gás, em maio de 1994. O obituário mencionava um livro em fase final de produção, With Broadax and Firebrand. Ele foi publicado no Brasil, dois anos depois, com o título de A Ferro e Fogo, que contou com a revisão técnica de José Augusto Drummond, hoje professor do Centro de Desenvolvimento Sustentável da Universidade de Brasília, e também autor de uma das resenhas mais detalhadas e perspicazes sobre o livro (DRUMMOND, 1996). Embora laureando-o com o adjetivo de "obra-prima", Drummond levantou críticas sobre um ponto-chave do livro, a saber, a relação entre devastação ambiental e equidade social: "não teríamos necessariamente mais justiça social se tratássemos nossas florestas com mais racionalidade ou reverência." Drummond prosseguiu para argumentar que A Ferro e Fogo tinha criado uma caricatura ambiental injusta e imprecisa dos personagens humanos do livro, mesmo que os personagens não humanos (ambientais) tivessem sido retratados precisamente: "os brasileiros acabam injustamente estigmatizados como excepcionais destruidores de florestas e sofríveis produtores de riquezas" (DRUMMOND, 1996, pp. 247, 248).

Como mostrou o estudo historiográfico de João Rafael Oliveira (2013), Dean vinha desenvolvendo os argumentos que apareceriam em A Ferro e Fogo havia muitos anos. Em uma resenha sobre o livro de Joe Foweraker, publicado em 1981, que tratava sobre a fronteira agrícola brasileira sob a ótica da economia política, Dean expressou extrema consternação a respeito do que ele via como um desperdício colossal ocorrendo na fronteira de expansão agrícola:

[...] qualquer um que viaja pela fronteira brasileira avista uma cena de puro horror: assalto genocida sobre povos tribais, devastação pelo fogo e pela motosserra de florestas climáxicas insubstituíveis e despossessão e massacre de agricultores pioneiros. Tudo isso numa escala inimaginável, sendo ao mesmo tempo algo fútil e bárbaro, pois produz apenas um lucro evanescente, além de terras nuas e degradadas [wasteland] como legado (DEAN, 1984, p. 1193).

Como ele posteriormente escreveu em A Ferro e Fogo, numa toada bem semelhante, "avareza é uma palavra pálida demais para descrever" a devastação da Mata Atlântica, "e a própria avareza é apenas uma falha menor do caráter comparada com a ignorância, indiferença e alienação que a acompanharam" (DEAN, 1996, p. 380).

Para John McNeill (2010, p. 336), A Ferro e Fogo é uma "obra-prima de pesquisa e um modelo de reflexão acadêmica politicamente comprometida", mas também "completamente dentro da tradição declensionista" de narrativa histórica e "consistente com a raubwirtschaft (economia de rapina), tema proeminente na geografia histórica latino-americana". ${ }^{1}$ Oliveira (2013) enfatiza, como influência ideológicas de Dean, a geografia norte-americana, particularmente a chamada Escola de Berkeley (MATHEWSON \& SEEMAN, 2008). Conforme ressaltado pelo próprio Dean, em entrevista concedida a José Augusto Drummond, "tenho realmente uma ligação com os geógrafos e leio os seus trabalhos com mais interesse do que os de qualquer outro grupo" (OLIVEIRA, 2013, p. 139). Ainda assim, é importante assinalar que a Escola de Berkeley não era inteiramente "de-

\footnotetext{
${ }^{1}$ De acordo com Glacken (1956, p. 85), no início do século XX, o geógrafo alemão Ernst Friedrich considerava a Raubwirtschaft (economia predatória) como uma fase "temporária" de uso voraz e descontrolado dos recursos naturais, sendo normalmente sucedida por uma maior consciência dos limites e necessidade de conservação. Como uma forma de historiografia, o termo declensionismo denota a ênfase na decadência e no colapso ambiental, uma "monótona e repetitiva narrativa sobre infortúnio" (McNeill, 2010, p. 359). Isto contrasta com outros modos de escrever a história que conferem menos peso a "perda e degradação", dando espaço a tradeoffs e surpresas.
} 
clensionista" quanto ao estilo narrativo e certamente não estava em dívida com ao paradigma da Raubwirtschaft, desenvolvido no começo do século XX por Ernst Friedrich e cujo objetivo era entender os estágios do desenvolvimento econômico (GLACKEN, 1956, p. 85).

A resenha que escrevi sobre $A$ Ferro e Fogo evitou abordar essas complicadas questões ideológicas, sugerindo, ao invés disso, como os geógrafos poderiam se beneficiar da leitura do livro. Eles poderiam aprender muito com a metodologia histórica de Dean: por exemplo, ele tinha um talento extraordinário para encontrar fontes ao reler e esquadrinhar textos conhecidos, localizando materiais excelentes, mas de difícil acesso. No sentido inverso, os geógrafos poderiam fornecer detalhes ausentes no relato de Dean a respeito de processos que operavam em escalas mais locais, em contraste com o bioma como um todo. Por fim, eu sugeri que o trabalho de Dean revelava a necessidade de estudos mais carregados de dados de campo sobre os processos de desflorestamento e seus impactos - estudos que os geógrafos estavam bem capacitados (teórica e metodologicamente) para realizar (BRANNSTROM, 1995).

Olhando para fora do campo da geografia stricto sensu, um levantamento rápido mostra que o livro de Dean é freqüentemente citado em publicações relacionadas ao bioma Mata Atlântica. Cientistas sociais e naturais citaram A Ferro e Fogo várias centenas de vezes. Dentre as muitas publicações de 2015 que citaram o livro encontra-se, por exemplo, um estudo etnográfico de um povoado Caiçara no litoral sul do estado Rio de Janeiro; neste caso, A Ferro e Fogo foi utilizado para descrever o contexto espacial e ambiental da área de estudo (IDROBO, et al. no prelo). Pesquisadores da área de ecologia citam o trabalho de Dean regularmente, normalmente de forma aprovativa, mas um grupo recentemente argumentou que Dean interpretou equivocadamente 0 Cerrado como um "produto da degradação florestal", o que teria ajudado a perpetuar um viés sobre a importância ecológica do fogo naquele bioma (DURIGAN \& RATTER 2016).

Na seara histórica, não seria exagero dizer que a obra de Dean ajudou a "fundar" a subdisciplina da história ambiental no Brasil. Embora ele já tivesse publicado uma história da borracha alguns anos antes (DEAN, 1989b), o escopo de A Ferro e Fogo - que investiga a área economicamente mais dinâmica do território brasileiro - foi incomparavelmente mais importante em termos de fronteira do conhecimento. Nas quase 500 páginas do livro, os historiadores brasileiros encontraram uma nova maneira de narrar e analisar o desenvolvimento socioeconômico do país. $\mathrm{Na}$ literatura brasileira, é difícil encontrar um trabalho pós-1996, mesmo que não trate de história florestal, que não renda homenagem a Ferro e Fogo. ${ }^{2}$ Contudo, longe de uma atitude puramente reverencial, os estudiosos brasileiros dialogam criticamente com o livro até hoje. Por exemplo, José Augusto Pádua (2015, p. 233) recentemente descreveu A Ferro e Fogo como "um clássico da história ambiental brasileira" e procurou colocar em prática as reivindicações de Dean, que admoestou seus leitores a usar as lições da Mata Atlântica para considerar as conseqüências da devastação da Amazônia. Na mesma edição da Revista de História Regional, Ely Bergo de CarvaIho (2015) forneceu uma discussão detalhada sobre a Floresta com Araucária (Floresta Ombrófila Mista), no contexto da qual criticou Dean por não problematizar a sua própria visão "cultural" do que seria a Mata Atlântica (uma crítica semelhante é feita por CASTRO [no prelo]).

Quando olhamos para a literatura em língua inglesa, também vemos discussão e diálogo rigorosos com a obra de Dean. Considere-se, por exemplo, a extensa crítica de Shawn William Mil-

\footnotetext{
${ }^{2}$ Não por acaso, uma recente tese de doutoramento foi dedicada à trajetória intelectual de Dean (OLIVEIRA, 2013).
} 
ler, que faz uma importante distinção entre o estudo do que as pessoas fizeram com as florestas e o que elas fizeram às florestas; enquanto $A$ Ferro e Fogo descreveu o período colonial como pura e simplesmente destrutivo, Miller (2000, p. 232) argumentou, de maneira mais sutil e nuançada, que a indústria madeireira colonial oferecia "a oportunidade para a sustentabilidade", um veredicto bem menos duro sobre o impacto da sociedade e das políticas coloniais sobre a Mata Atlântica. Em contraste, Michael Williams, autor de uma aclamada história global do desflorestamento, usou as alegações de Dean sobre "imprevidência e parasitismo" (DEAN 1996, p. 24) para argumentar que a devastação da Mata Atlântica "deve ser classificada como um dos episódios mais vorazes, completos, profundos e, no limite, talvez desnecessários e insensatos, nos anais do desflorestamento da Terra" (Williams 2003, p. 378). Notavelmente, esse tipo de argumento é o que Drummond (1996) havia criticado anos antes, na sua resenha sobre A Ferro e Fogo. Mais recentemente, Case Watkins e Robert Voeks (no prelo) contestaram a caracterização feita por Dean sobre os africanos escravizados: "refugiados em terra alienígena", indivíduos que seriam meros veículos do "saber vagamente rememorado dos indígenas" (DEAN, 1996, pp. 106, 117). Por meio de dados arquivísticos, etnográficos e geoespaciais, os autores retrataram os afrodescendentes como atores que, por meio de seu conhecimento ecológico, promoveram um intenso intercâmbio cultural e biológico entre a Mata Atlântica e as florestas tropicais da África ocidental.

Entre os geógrafos brasileiros, contudo, houve um engajamento bastante limitado com $A$ Ferro e Fogo. Aparentemente, muitos geógrafos brasileiros abandonaram os estudos históricos, embora haja importantes exceções, como a análise da territorialidade colonial no "longo século XVI" feita por Antonio Carlos Robert de Moraes (2000), o estudo da evolução urbana de Salvador na longa duração por Pedro Vasconcelos (2002) e a obra pioneira de Mauricio Abreu (2010) sobre os dois primeiros séculos do Rio de Janeiro; de qualquer forma, fica claro que a geografia histórica brasileira não acompanhou o ritmo da história ambiental brasileira. Em parte, isso é explicado pelo tamanho da comunidade científica: em contraste com o mundo anglo-saxão, por exemplo, a comunidade geográfica brasileira é comparativamente pequena. Além do grupo liderado por Abreu, na Universidade Federal do Rio de Janeiro - agora infelizmente extinto, mas que encontrou continuação em torno de Marcelo Werner da Silva, um discípulo de Abreu, na Universidade Federal Fluminense - há poucos laboratórios e grupos de pesquisa em geografia histórica. É natural que, num universo restrito, não haja grande diversificação teórico-metodológica e temática. Os geógrafos históricos brasileiros tendem a ser geógrafos humanos com muito pouco interesse na dimensão biofísica da espacialidade humana; eles seguem uma abordagem "territorial" essencialmente inspirada na obra de Milton Santos e quase sempre centrada no mundo urbano. ${ }^{3}$

Santos é uma figura-chave para se compreender a geografia brasileira das últimas décadas do século $X X$ - sua força, sua autoconfiança, seu desenvolvimento teórico, mas também seus vieses. A sua influência explica muito da ignorância geográfica, no Brasil, em relação à obra de Dean. Não poderia ser mais significativo que, no mesmo ano da publicação de $A$ Ferro e Fogo, aparecia também A Natureza do Espaço, obra magna de Santos. Neste livro, ele expõe a sua magnificamente construída teoria do espaço geográfico, sinteticamente definido como a "união indissociável de sistemas de objetos e sistemas de ações" (SANTOS, 1996, p. 18). Embora tenha bebido em diversas outras fontes filosóficas, a teoria miltoniana do espaço é basicamente uma

\footnotetext{
${ }^{3}$ Agradeço a Maria Lúcia Vilarinhos por me alertar para o "urbanocentrismo" da geografia brasileira e a Diogo Cabral (2016) pelo texto não publicado sobre Milton Santos.
} 
teoria neomarxista da artificialização do ambiente. Com o progressivo e inexorável controle técnico das forças naturais, a dialética do espaço restringe-se à contradição entre o "trabalho vivo" - os esforços produtivos presentes - e o "trabalho morto" - os esforços objetificados e cristalizados como ambiente construído. A natureza torna-se "segunda natureza", natureza domesticada que é quase um epifenômeno da ação humana. "Cria-se uma configuração territorial que é cada vez mais o resultado de uma produção histórica e tende a uma negação da natureza natural, substituindo-a por uma natureza inteiramente humanizada" (SANTOS, 1996, p. 51).

Concebida como o artefato humano por excelência, a cidade, sobretudo a grande cidade, comanda o processo de tecnificação. A sua complexidade socioespacial, advinda de "ecologias sociotécnicas recriadas ao longo da história urbana", permite que elas recebam "todos os tipos de capital e todos os tipos de trabalho". Como imensas aglomerações demográficas, sobretudo de populações pobres, as cidades criam "sociodiversidades" que podem ser consideradas mais importantes que a própria biodiversidade (SANTOS, 1996, pp. 245, 258-9). Isso foi categoricamente reafirmado no último livro de Santos, Por uma outra globalização: "Trata-se da existência de uma verdadeira sociodiversidade, historicamente muito mais significativa que a própria biodiversidade" (SANTOS, 2001, p. 21). Como até as matérias-primas industriais - os "novos materiais", como o plástico - já são elas mesmas produzidas pelo trabalho humano, os espaços verdadeiramente naturais, as "ecologias selvagens" não parecem mesmo ter qualquer importância na vida urbana.

É difícil exagerar a distância teórica que separa essa perspectiva - exposta naquele que talvez seja o livro mais influente da história recente da geografia brasileira - daquela que embasa $A$ Ferro e Fogo. O tecnocentrismo miltoniano é muito dificilmente conciliável com a assunção básica dos historiadores ambientais, qual seja, a de que há um mundo que permanece, e sempre permanecerá incontrolável, infabricável pelos humanos, e que essa dimensão intrinsecamente telúrica do ambiente ajuda a moldar o que os geógrafos chamam de território, ou espaço geográfico (CABRAL, 2014a). Conforme escreveu José Augusto Drummond no clássico artigo em que apresenta a história ambiental - até então um empreendimento basicamente estadunidense - aos brasileiros:

Não há meias palavras quanto a isso. Não se trata de fazer apenas metáforas ambientais, ecológicas ou naturais, como as que predominaram, por exemplo, na famosa escola de 'ecologia humana' desenvolvida na Universidade de Chicago a partir dos anos 1920 [...]. Trata-se de uma mudança séria de paradigma nas ciências sociais. Significa que o cientista social dá às 'forças da natureza' um estatuto de agente condicionador ou modificador da cultura (DRUMMOND, 1991, p. 181).

Inteiramente comprometida com essa mudança de paradigma, a obra de Dean não pretendia abordar, simplesmente, o aproveitamento econômico da floresta, a indústria madeireira, a silvicultura e atividades correlacionadas, limitando a narrativa "ao manejo de arvoredos desgalhados e podados e de macabras reservas de caça"; o livro não pretendia estudar esses "campos de concentração para o mundo natural", mas o encontro humano com esse mundo, isto é, com os ecossistemas florestais em toda a sua complexidade e pujança vital - "sociedades compostas de miIhares de espécies de plantas e animais". Não se tratava também de uma história puramente natural ou ecológica, de "uma explicação das criaturas da floresta e das relações que estas mantêm entre si", mas de "um estudo da relação entre a floresta e o homem" (DEAN, 1996, pp. 22, 28). Essa atitude teórico-metodológica foi bem formulada pelo acadêmico marxista James O'Connor, alguns anos mais tarde: 
Eles [os historiadores ambientais] estudam mudanças na atividade humana e na economia da natureza, não em isolamento, mas em termos das suas interações. História natural e história humana são vistas como dois lados dos mesmos processos gerais; elas se modificam mutuamente e, no limite, determinam-se mutuamente. Assim, é impossível (em muitos ou na maioria dos casos, se não em todos) extrair setas causais simples entre a história natural e a humana, as quais se constituem entre si. Há uma 'conexão interna' entre as duas; elas são tanto o contexto quanto o conteúdo uma da outra (O'CONNOR, 1998, p. 25).

É preciso sublinhar que esse paradigma "socionatural" não é incompatível com a temática urbana. Embora as primeiras décadas de desenvolvimento da disciplina, nos Estados Unidos, tenham sido marcadas por um certo apego ao rural e à mudança ambiental agrícola, uma nova geração de historiadores ambientais - inclusive no Brasil (ver, e.g. CABRAL, 2011; MAIA \& SEDREZ, 2011; CABRAL et al., no prelo) - vem procurando incluir as cidades em seu horizonte de preocupação, investigando "como elas interagem com, influenciam ou modificam o mundo natural enquanto um sistema social/espacial animado" (MELOSI, 1993, p. 11). Usando uma abordagem parecida com a empregada por William Cronon, em seu magnífico Nature's Metropolis (1991), Dean procura retratar as cidades da Mata Atlântica não apenas como centros irradiadores de mudança ambiental, mas também como assentamentos humanos sustentados pelos ecossistemas locais e regionais. Uma das grandes questões que A Ferro e Fogo abordou, embora não com a profundidade necessária, foi a drenagem de recursos que a cidade de São Paulo efetuou na sua vasta hinterlândia. É interessante observar o arco histórico na própria carreira de Dean: seu primeiro livro, sobre a industrialização de São Paulo, ignorou o tema dos recursos naturais, com exceção da hidroeletricidade, que ele equivocadamente assumiu - mas corrigiu, posteriormente, em A Ferro e Fogo - ter suprido a energia para a industrialização. Segundo o obituário escrito por Robert Levine (1994), depois de A Ferro e Fogo, Dean estava "planejando uma 'oncologia' da cidade de São Paulo". Fica-se a imaginar se essa "oncologia" se referia à caracterização da cidade como um crescimento cancerígeno, sugando à exaustão os recursos de seu organismo hospedeiro, a Mata Atlântica. Certamente, os diversos aspectos desses processos de drenagem de recursos são mais do que adequados à pesquisa geográfica.

Mas o fato é que, guardadas as diferenças temáticas e metodológicas entre as duas obras, os geógrafos brasileiros nunca debateram com A Ferro e Fogo com a mesma intensidade com que os geógrafos norte-americanos debateram com Nature's Metropolis, obra que ajudou a inspirar toda uma geração de jovens acadêmicos, na geografia e na história, a desenvolver temas histórico-ambientais de pesquisa. Em 1994, a revista geográfica de política "radical" Antipode dedicou um número especial a debater a obra de Cronon; após elogiarem o livro, muitos geógrafos argumentaram que Ihe faltava o tipo de teoria capaz de promover generalizações e uma crítica mais ampla de como o capitalismo consome a natureza, além do papel do trabalho na conversão da "primeira" em "segunda" natureza. Cronon (1994) respondeu argumentando que seu livro teria se tornado insuportavelmente tedioso e difícil de ler caso tivesse seguido o conselho de seus críticos. Para além deste incidente, houve muito diálogo profícuo entre historiadores e geógrafos a respeito dos ambientes do passado, tanto na perspectiva geográfica quanto na perspectiva histórica. Conforme mostrou a revisão de Felix Driver (2013) sobre a geografia histórica, a pesquisa histórico-ambiental perfaz parte importante da produção norte-americana e européia. No Brasil, entretanto, tanto o tamanho reduzido da comunidade geográfica quanto o seu viés "desnaturalizador" dificultaram muito o diálogo com a história ambiental. 
Sendo assim, o pouco diálogo que houve com A Ferro e Fogo foi produto da iniciativa de "geógrafos físicos" e geógrafos humanos menos ortodoxos. Um desses pesquisadores da área "física" foi Rogério Oliveira, em torno do qual se formou um dinâmico grupo de ecologia histórica, na Pontifícia Universidade Católica do Rio de Janeiro. Embora o seu diálogo com A Ferro e Fogo seja, em grande parte, indireto - sobretudo porque o seu ponto de partida é a ecologia presente da paisagem local -, eles aprofundaram as investigações de Dean (1996, pp. 190-192, 211-212) a respeito de dois pontos: o consumo florestal dos engenhos açucareiros e o abastecimento de biomassa combustível da cidade do Rio de Janeiro, no final do século XIX. Trabalhando com os vestígios materiais na paisagem do Maciço da Pedra Branca, na zona oeste da cidade, Oliveira e seu grupo estimaram o volume de biomassa consumido por um engenho beneditino, na década de 1770 (ENGEMANN et al., 2005). Em outros trabalhos, eles mostraram uma forte relação entre crescimento urbano, produção de carvão nas encostas e população negra, sobretudo ex-escravos provenientes dos antigos engenhos de açúcar das baixadas (OLIVEIRA et al., 2011; OLIVEIRA \& FRAGA, 2011). Eles identificaram vestígios de mais de mil antigas carvoarias, a quase totalidade dentro de atuais formações florestais, além de 81 baldrames de antigas moradias no interior de um parque estadual (OLIVEIRA, 2015). Ainda outro trabalho analisa textos agrícolas coloniais, concluindo que existia um alto grau de preocupação ambiental nos mesmos (OLIVEIRA \& WINIWARTER 2010).

Outro grupo de geógrafos e geólogos claramente motivados, pelo menos em parte, pelo trabalho de Dean concentrou esforços em descrever e analisar os chamados "depósitos tecnogênicos" (OLIVEIRA, et al. 2005). Análogos ao legado sedimentar (JAMES 2013) ou sedimentação pós-aluvial, tais depósitos são constituídos por erosão do solo acionada por desflorestamento e usos agrícolas da terra, resultando em acumulação de material nas planícies de inundação fluviais. Esse tipo de trabalho reconstrói a cobertura da terra anterior ao desflorestamento para identificar os processos que encorajaram a erosão medida a partir das características dos depósitos. Publicada antes de A Ferro e Fogo e antes da invenção do termo "Antropoceno", o trabalho de Antônio Manoel dos Santos Oliveira demonstrou impactos materiais tangíveis do desflorestamento pretérito, com particular relevância para os esforços de manejo em curso (OLIVEIRA \& QUEIROZ NETO, 1994). Trabalhos posteriores cobrindo diversos sítios, sobretudo no estado de São Paulo, lançaram nova luz sobre um tipo de história ambiental que rastreia de perto as árvores (FRANÇA JUNIOR \& SOUZA, 2014; PELOGGIA et al., 2014; BRANNSTROM \& OLIVEIRA, 2000; PELOGGIA, no prelo). O estudo dos depósitos tecnogênicos oferece uma nova perspectiva para narrativas histórico-ambientais como aquela de $A$ Ferro e Fogo - que procura obsessivamente pela última árvore de pé (BRANNSTROM, 2004) -, oferecendo, adicionalmente, uma análise das relações entre manejo hídrico e planejamento urbano.

Outro geógrafo ambiental brasileiro cujo trabalho dialogou intensamente com Dean foi Diogo de Carvalho Cabral. Em seus trabalhos mais recentes, Cabral assumiu uma postura muito crítica em relação a Ferro e Fogo. Em um artigo de 2008, ele argumentou que o "declensionismo" de Dean deriva da desconsideração da dimensão cultural da economia colonial brasileira. Partindo de uma concepção "substantivista" da economia, Cabral sustentou que, ao ignorar a dinâmica "arcaizante" da sociedade colonial - i.e., a motivação nobiliárquica de se distinguir como "senhor de terras e homens" - Dean não compreendeu que a posse de escravos era, de fato, um indicador de riqueza e de vitalidade econômica, embora não fosse, evidentemente, um caminho para o capita- 
lismo e para o desenvolvimento econômico. Sem essa compreensão, restava a Dean insistir na congênita rapacidade e perdularidade dos portugueses e brasileiros (CABRAL, 2008). Em seu livro Na Presença da Floresta, Cabral (2014b) oferece várias correções à obra de Dean. Por exemplo, ele compara as estimativas de desflorestamento para o Brasil colonial e para a América do Norte colonial, argumentando que a área relativamente modesta devastada no Brasil enfraquece a alegação de Dean sobre destruição generalizada e tragédia florestal. Cabral argumenta que a busca desenfreada por evidências de comportamento predatório acabou levando Dean a equívocos, inclusive de interpretação das fontes. O exemplo mais cabal é a citação de um cronista do final do século XVI, Gabriel Soares de Sousa, que, comentando acerca da fertilidade dos solos da Bahia, escreve que "vale mais a novidade de uma fazendo que a sua propriedade". O problema é que, no vocabulário quinhentista de Sousa, "novidade" significa "colheita", "produto de algo semeado"; no final das contas, portanto, Sousa estava dizendo que, a preços de mercado, as colheitas valiam mais do que os direitos de propriedade sobre a terra (CABRAL, 2014b, pp. 463-4, 446-7).

Mas, em outras oportunidades, Cabral também reconheceu os méritos de A Ferro e Fogo, na forma dos inúmeros insights que abriram fronteiras de conhecimento sobre a história do território brasileiro. Em um trabalho recente, ele procurou aprofundar uma das afirmações mais provocantes e inovadoras de Dean (1996, p. 125): "Se, nos primeiros 450 anos do Brasil, tivessem existido meios de combater a saúva, sua agricultura e, conseqüentemente, sua história teriam sido muito diferentes". Cabral examinou a literatura biológica sobre as saúvas publicada depois de $A$ Ferro e Fogo para mostrar que o desflorestamento foi responsável pela explosão demográfica de diversas espécies de formigas cortadeiras. Ao mesmo tempo, condições edáficas desencorajadoras da saúva (os famosos massapés, solos muito pegajosos que dificultam a construção de ninhos) explicam parte do sucesso da cana de açúcar no nordeste, sobretudo em Pernambuco (CABRAL, 2015).

Embora mantenha fortes laços com o Brasil, o autor destas linhas é um geógrafo formado na tradição histórico-ambiental da Escola de Berkeley (MATHEWSON \& SEEMAN, 2008). Na Universidade de Wisconsin-Madison, fui orientado por dois dos maiores expoentes da geografia histórico-ambiental estadunidense (William Denevan e Karl Zimmerer). Esse tipo de formação, em contraste com o ambiente intelectual mais segmentado da geografia brasileira ("humanos" vs. "físicos"), explica o meu engajamento quase natural com a obra de Dean. Eu tentei questionar ou "testar" algumas das afirmações de A Ferro e Fogo, reconhecendo que muitos dos insights de Dean eram baseados em evidência parcial ou limitada que podia não ser aplicável a todo o bioma. Por exemplo, eu argumentei que a noção biogeográfica de Mata Atlântica usada por Dean pode ter sido excessivamente inclusiva (BRANNSTROM, 2002). Eu também tentei reformular, com maior detalhamento empírico, a hipótese de Dean a respeito do uso de madeira combustível no processo de industrialização de São Paulo (BRANNSTROM, 2012). Em outro artigo, eu me concentrei nos usos da terra que se seguiram ao desflorestamento, analisando a expansão da lavoura algodoeira no estado de São Paulo (BRANNSTROM, 2010). Algo que A Ferro e Fogo me ensinou foi a procurar vozes contrárias ao desflorestamento desenfreado; o artigo mostrou que houve certos constrangimentos no seio da própria organização que estava promovendo a expansão do algodão (BRANNSTROM, 2010).

Por último, vale a pena mencionar uma dificuldade adicional na "digestão" de A Ferro e Fogo pelos geógrafos brasileiros, a saber, o exacerbado "conceitualismo" que a comunidade desenvol- 
veu nas últimas décadas do século XX. Passagens como aquela em que Dean (1996, p. 24), logo na introdução do livro, define "espaço" como as "planícies desertas aplainadas a rolo compressor e sobre as quais o extremo do narcisismo da espécie se consagra em edificações" podem ter assustado e afastado potenciais interlocutores. Talvez até mais do que outras comunidades nacionais, os geógrafos brasileiros adquiriram um imenso orgulho de seus conceitos fundadores, sobretudo o de espaço, que eles geralmente consideram expressar o cerne de sua identidade profissional (CORRÊA, 2000). Encarado principalmente, embora não exclusivamente, sob o aspecto locacional (CORRÊA, 1986), o espaço - enquanto distribuição e organização espacial - é considerado indispensável a um trabalho genuinamente geográfico. Neste espírito, ainda que Dean tenha incluído uma série de mapas em seu livro (mapas que retratam a posição dos fatores e vetores de desmatamento no contexto do bioma Mata Atlântica), muitos geógrafos argumentariam que não são mapas propriamente analíticos, mas apenas descritivos ou ilustrativos.

Mas mapeamento e análise espacial não são incompatíveis com história ambiental, conforme mostrei em outro trabalho (BRANNSTROM, no prelo). Combinando diversos tipos de fontes, eu expus a relação entre a distribuição de serrarias, a rede ferroviária e as formações vegetais do estado de São Paulo, além de explorar mais detalhadamente as relações comerciais e de trabalho em dois dos "nós" da indústria madeireira (Assis e Londrina). Num nível mais avançado de sofisticação computacional, muitos geógrafos e historiadores ambientais têm se voltado para os Sistemas Histórico-Geográficos de Informação, ou SIGs Históricos. Em estreito diálogo com A Ferro e Fogo, Frederico Freitas (2013) estudou a pressão da agropecuária sobre a Mata Atlântica através de inventários post-mortem lavrados entre meados do século XVIII e meados do XIX. Realizando uma análise de densidade (Kernel Density), Freitas conseguiu mostrar uma relação significativa entre desflorestamento, lavoura de corte-e-queima e criação de porcos, na região centro-sul do atual estado de Minas Gerais.

Um exame retrospectivo desse clássico da história ambiental brasileira que é $A$ Ferro e Fogo mostra que há diversas áreas e temas tratados no livro que os geógrafos brasileiros, especialmente aqueles trabalhando com abordagens históricas, estão mais do que preparados para desenvolver. Apesar de seus insights sobre os efeitos ambientais do crescimento e industrialização de cidades como São Paulo e Rio de Janeiro, Dean não se aprofundou muito na história ambiental urbana, entendida como um campo que abarca tanto a natureza dentro da cidade, como as transformações nos canais fluviais e na fauna urbana, quanto a natureza para a cidade, ou os recursos e materiais que os ecossistemas locais e regionais fornecem para a produção industrial, acumulação de riqueza e formação de elites sociais. A primeira dimensão já constitui um grande tema na escrita da história ambiental, enquanto a segunda, seguindo os passos de Nature's Metropolis (CRONON, 1991), tem um largo potencial para avançar a discussão entre Drummond e Dean a respeito do papel da exploração dos recursos naturais na reprodução das desigualdades sociais e econômicas no Brasil.

O mesmo exame retrospectivo mostra que abordagens biográficas e institucionais - tais como a que Dean desenvolveu não somente em A Ferro e Fogo, mas também em A Luta pela 
Borracha - ainda não tiveram seu potencial inteiramente explorado. Mesmo que esse tipo de estudo não abarque a totalidade do bioma, ele pode oferecer novas perspectivas sobre a dinâmica histórica da Mata Atlântica. Atualmente, estamos assistindo a um revigoramento dos estudos biográficos entre os geógrafos históricos (LAMBERT, 2013; OGBORN, 2008; LESTER, 2012). Essa abordagem pode ser aplicada a tópicos ambientais, seguindo os rastros das numerosas histórias contadas por Dean sobre conservacionistas que lutaram para proteger a Mata Atlântica. Os trabaIhos de Elenita Pereira $(2011,2015)$ sobre José Lutzenberger e de Sandro Dutra e Silva (2012) sobre Bernardo Sayão, por exemplo, avançam exatamente nessa direção. Pádua (2002) já havia feito algo semelhante em certo capítulo de seu livro, quando examinou o caso de José Bonifácio, mas ainda há muito a ser explorado, especialmente com relação a cientistas desconhecidos e suas redes de conhecimento.

Outra área que merece mais atenção é o estudo dos depósitos tecnogênicos. De maneira associada ao mapeamento e às análises sedimentológicas que geógrafos e geólogos têm realizado nos últimos vinte anos, é possível problematizar os processos políticos e econômicos envolvidos no desflorestamento e na mudança de uso da terra. Nós apenas começamos a compreender esses processos centrados na atividade humana e que geram impactos tangíveis nas paisagens fluviais, mesmo que já tenhamos estabelecido registros sedimentológicos detalhados. O desflorestamento não protagoniza apenas uma história de destruição e desperdício, mas também de construção de novas paisagens que oferecem novos desafios aos seus habitantes humanos; é preciso contar as histórias da vida pós-desflorestamento. Esse trabalho possui um grande potencial de multidisciplinaridade, na medida em que incorpora a expertise de geógrafos físicos, geólogos e engenheiros, entre outros, tendo valor gerencial prático para os tomadores de decisão. Ele também aborda uma grande omissão da história de devastação contada por Dean, já que nos encoraja a pensar para além das florestas, nas muitas conseqüências do desflorestamento, incluindo a oferta de água potável e o planejamento urbano, questões prementes no Brasil atual.

Embora intensivos em trabalho de campo - portanto altamente dispendiosos -, os esforços empreendidos por Rogério Oliveira e seu grupo, descobrindo centenas de paleo-carvoarias e dezenas de ruínas habitacionais, mereceriam ser estendidos a outras áreas da Mata Atlântica. Quantos desses vestígios paisagísticos poderiam ser encontrados, sobretudo nos arredores das grandes cidades da Mata Atlântica? Quantos deles estariam escondidos em áreas atualmente cobertas com floresta? Como essas economias e populações carvoeiras alteram a história contada em A Ferro e Fogo? Será que esse tipo de evidência não transforma a história da Mata Atlântica num enredo sobre lutas sociais, cadeias de suprimento material e "paisagens interativas" mais do que sobre desperdício e destruição? Em um artigo a ser publicado em breve, Diogo Cabral e colaboradores tentam avançar nesta direção, conectando urbanização, produção carvoeira e reprodução social e cultural de ex-escravos com a adaptação e transformação da vegetação local (CABRAL et al., no prelo).

Last but not least, há a possibilidade de se avançar na investigação "espacial" ou "territorial" da história da Mata Atlântica e das florestas brasileiras em geral, uma abordagem naturalmente atraente para os geógrafos. Aqui, no entanto, é preciso afrouxar um pouco as amarras conceituais a fim de encampar os múltiplos significados de espaço e território, assim como as diferentes formas de sua objetivação científica. Pelo lado mais analítico-quantitativo do problema, a história do desmatamento e transformação ambiental pode ser abordada através de SIGs alimentados por 
documentação histórica, como inventários post-mortem, escrituras de compra e venda, levantamentos topográficos, e até fontes menos evidentemente "ambientais", como processos criminais. Embora Brannstrom $(2000,2002)$ já tivesse realizado mapeamentos históricos com base em documentos cartorários, o artigo de Freitas (2013) foi um dos primeiros a analisar quantitativamente esse tipo de fonte.

Num viés mais qualitativo e narrativo, Cabral (2014a) propôs o estudo da formação do território brasileiro não como "ocupação", mas como "encontro" e "adaptação". Partindo da concepção do território como uma dimensão de contato, um "terreno comum" de que todos os seres e coisas naturais necessariamente participam - inclusive os humanos -, Cabral reivindicou a substituição da narrativa do preenchimento europeu de um meio vazio e inerte pela história dos ajustamentos recíprocos entre os recém-chegados e os solos, plantas, animais e climas que eles encontraram, nos caminhos da colonização. Essa perspectiva de um espaço ecologicamente "cheio", composto por "lugares concretos e suas características biofísicas", também vem sendo adotada por Pádua. Em um de seus últimos artigos, ele procurou comparar a dinâmica histórico-regional dos dois grandes biomas florestais do Brasil: Mata Atlântica e Amazônia (PÁDUA, 2015). Vislumbrada por Dean, essa "história ambiental comparativa" do território brasileiro parece ser, de fato, uma das fronteiras mais importantes da disciplina, no Brasil. ${ }^{4}$

Todas essas são grandes e profundas questões sobre a história da Mata Atlântica, questões que os geógrafos brasileiros podem ajudar a responder. A Ferro e Fogo continua a oferecer um conjunto de pontos de partida extremamente úteis para a renovação e revigoramento da geografia histórica do território brasileiro, mesmo que entre em conflito com noções consagradas na comunidade geográfica nacional. Aparentemente, esse problema vem se tornando cada vez menor, na medida em que a geografia brasileira cresce quantitativamente e se diversifica temática, teórica e metodologicamente. Muito mais e melhor do que vinte anos atrás, os pesquisadores brasileiros parecem preparados para travar o desafiador combate intelectual que é dialogar com $A$ Ferro $e$ Fogo, entrando num debate interdisciplinar com os historiadores ambientais e incluindo as relações socioambientais dentro da geografia humana do país.

\footnotetext{
${ }^{4}$ Por exemplo, o trabalho recente de Cushman (2013) sobre a pesca da anchoveta peruana envolve cientistas, industrialistas, trabalhadores e políticos numa história ambiental global.
} 
ABREU, M.A. Geografia Histórica do Rio de Janeiro (1502-1700). Rio de Janeiro: Andrea Jakobsson Estúdio Editorial, 2010. 2 v.

BRANNSTROM, C. Review: With Broadax and Firebrand. Annals of the Association of American Geographers v.85, n.4, p. 745-748, 1995.

. Coffee labor regimes and deforestation on a Brazilian frontier, 1915-1965. Economic Geography v.76, n.4, p. 326-46, 2000.

. Repensando a Mata Atlântica brasileira: cobertura vegetal e valor de terra no Oeste Paulista, 1900 a 1930. Varia História v.26, p. 58-76, 2002.

. Talking to sediments: reading environmental history from post-settlement alluvium in Western São Paulo, Brazil. In: BRANNSTROM, C. (Ed.), Territories, Commodities and Knowledges: Latin American Environmental History in the Nineteenth and Twentieth Centuries. London: Institute for the Study of the Americas, 2004, p. 171-191.

. Forests for cotton: institutions and organizations in Brazil's mid-twentieth-century cotton boom. Journal of Historical Geography v.36, n.2, p. 169-82, 2010.

. A madeira foi o combustível que moveu a industrialização brasileira? Avaliando a hipótese da madeira, 1900-1960. In: DRUMMOND, J.A., FRANCO, J.L.A.; DUTRA E SILVA, S. (Org.) História ambiental: fronteiras, recursos naturais e conservação da natureza. Rio de Janeiro: Garamond, 2012, p. 39-75.

A economia madeireira na Mata Atlântica interiorana, 1920-1960. In: CABRAL, D.C.; BUSTAMANTE, A.G. (Org.), Metamorfoses florestais: culturas, ecologias e as transformações históricas da Mata Atlântica. Curitiba: Prismas, no prelo.

BRANNSTROM, C.; OLIVEIRA, A.M.S. Human modification of stream valleys in the western plateau of São Paulo, Brazil: Implications for environmental narratives and management. Land Degradation and Development v.11, n.6, p. 535-48, 2000.

CABRAL, D.C. Substantivismo econômico e história florestal da América portuguesa. Varia História v.24, n.39, p. 113-133, 2008.

. Águas passadas: sociedade e natureza no Rio de Janeiro oitocentista. RA'E GA - O Espaço Geográfico em Análise v.23, p. 159-190, 2011.

. 'O Brasil é um grande formigueiro': território, ecologia e a história ambiental da América portuguesa, parte 1. Historia Ambiental Latinoamericana y Caribeña v.3, n.2, p. 467-489, 2014a.

Na presença da floresta: Mata Atlântica e história colonial. Rio de Janeiro: Garamond/FAPERJ, 2014b.

Into the bowels of tropical earth: Leaf-cutting ants and the colonial making of agrarian Brazil. Journal of Historical Geography v.50, n.4, p. 92-105, 2015.

. Milton Santos e a geografia histórica brasileira. Texto não publicado. 2016. 
CABRAL, D.C.; BUSTAMANTE, A.G. Introdução. In: (Org.) Metamorfoses florestais: culturas, ecologias e as transformações históricas da Mata Atlântica. Curitiba: Prismas, no prelo.

CABRAL, D.C.; SOLÓRZANO, A.; OLIVEIRA, R.R. Urbanising rainforests: emergent socioecologies in Rio de Janeiro, Brazil. Landscape History, no prelo.

CARVALHO, E.B. Problematizando as representações do mundo natural como delimitação espacial em história ambiental: entre a Araucarilandia e a Floresta Ombrófila Mista. Revista de História Regional v.20, n.3, p. 317-342, 2015.

CASTRO, L. Da província ao bioma: representações da Mata Atlântica. In: CABRAL, D.C.; BUSTAMANTE, A.G. (Org.), Metamorfoses florestais: culturas, ecologias e as transformações históricas da Mata Atlântica. Curitiba: Prismas, no prelo.

CORRÊA, R.L. O enfoque locacional na Geografia. Terra Livre v.1, p. 62-66, 1986.

Espaço, um conceito-chave da geografia. In: CASTRO, I.E.; GOMES, P.C.C.; CORRÊA, R.L. (Org.), Geografia: conceitos e temas. Rio de Janeiro: Bertrand Brasil, $2^{\mathrm{a}}$ ed., 2000.

CRONON, W. Nature's metropolis: Chicago and the Great West. New York: W.W. Norton and Co., 1991.

. Reply: On totalization and turgidity. Antipode v.26, n.2, p. 166-78, 1994.

CUSHMAN, G.T. Guano and the opening of the Pacific World: A global ecological history. New York: Cambridge University Press, 2013.

DEAN, W. Review: Joe Foweraker, The Struggle for Land. American Historical Review v.89, n.4, p. 1193, 1984.

The green wave of coffee: beginnings of tropical agricultural research in Brazil (18851900). Hispanic American Historical Review v.69, n.1, p. 91-115, 1989a.

A luta pela borracha no Brasil. São Paulo: Nobel, 1989b.

The tasks of Latin American environmental history. In: STEEN, H.K.; TUCKER R.P. (Ed.), Changing tropical forests: Historical perspectives on today's challenges in Central and South America. Durham: Forest History Society, 1992.

A ferro e fogo: a história e a devastação da Mata Atlântica brasileira. Trad. C.K. Moreira. São Paulo: Cia. das Letras, 1996 [1995].

DRIVER, F. Research in historical geography and in the history and philosophy of geography in the UK, 2001-2011: an overview. Journal of Historical Geography v.42, p. 203-11, 2013.

DRUMMOND, J.A. A história ambiental: temas, fontes e linhas de pesquisa. Estudos Históricos v.4, n.8, p. 177-197, 1991.

1996.

. Mata Atlântica: A história de uma destruição. Estudos Históricos v.9, n.17, p. 239-250,

DURIGAN, G.; RATTER, J.A. The need for a consistent fire policy for Cerrado conservation. Journal of Applied Ecology v.53, n.1, p. 11-15, 2016. 
DUTRA E SILVA, S. No caminho, um jatobá: enfrentamento e devastação da natureza na conquista do 'último oeste'. In: DRUMMOND, J.A., FRANCO, J.L.A.; DUTRA E SILVA, S. (org.) História ambiental: fronteiras, recursos naturais e conservação da natureza. Rio de Janeiro: Garamond, 2012.

ENGEMANN, C.; CHAGAS, J.; SANTOS, R.S.; BORGES, A.C.; OLIVEIRA, R.R. Consumo de recursos florestais e produção de açúcar no período colonial: o caso do engenho do Camorim, RJ. In: OLIVEIRA, R.R. (Org.), As marcas do homem na floresta: história ambiental de um trecho urbano de Mata Atlântica. Rio de Janeiro: PUC-Rio, 2005, p. 119-140.

FRANÇA JUNIOR, P. \& SOUZA, M.L. Tecnógeno em ambientes fluviais: noroeste do Paraná, Brasil. Quaternary and Environmental Geosciences v.5, n.2, p. 45-52, 2014.

FREITAS, F.S. Land use and deforestation in Southeastern Brazil, 1753-1841. Fronteiras - Journal of Social, Technological and Environmental Science v.2, n.2, p. 49-77, 2013.

GLACKEN, C. Changing ideas of the habitable world. In: THOMAS, Jr., W.L. (Ed.), Man's role in changing the face of the Earth. Chicago: University of Chicago Press, 1956, p. 70-92.

IDROBO, C.J.; DAVIDSON-HUNT, I.J.; SEIXAS, C.S. Produced natures through the lens of biodiversity conservation and tourism: the Ponta Negra Caiçara in the Atlantic Forest of Brazil. Local Environment, no prelo.

JAMES, L.A. Legacy sediment: Definitions and processes of episodically produced anthropogenic sediment. Anthropocene v.2, p. 16-26, 2013.

LAMBERT, D. Mastering the Niger: James MacQueen's African geography and the struggle over Atlantic slavery. Chicago: University of Chicago Press, 2013.

LESTER, A. Personifying colonial governance: George Arthur and the transition from humanitarian to development discourse. Annals of the Association of American Geographers v.106, n.6, p. 1468-88, 2012.

LEVINE, R.M. Obituary: Warren Dean (1932-1994). Hispanic American Historical Review v.74 n.4, p. 689-92, 1994.

MAIA, A.C.N; SEDREZ, L. Narrativas de um Dilúvio Carioca: memória e natureza na Grande Enchente de 1966. História Oral v.2, n.14, p. 221-254, 2011.

MATHEWSON, K. \& SEEMAN, J. A geografia histórico-cultural da Escola de Berkeley: Um precursor ao surgimento da História Ambiental. Varia Historia v.24, n.39, p. 71-85, 2008.

McNEILL, J.R. The state of the field of environmental history. Annual Review of Environmental Resources v.35, p. 345-74, 2010.

MELOSI, M.V. The place of the city in environmental history. Environmental History Review v.17, n.1, p. 1-23, 1993.

MILLER, S.W. Fruitless trees: Portuguese conservation and Brazil's timber. Stanford: Stanford University Press, 2000.

MORAES, A.C.R. Bases da formação territorial do Brasil: o território colonial brasileiro no 'Iongo' século XVI. São Paulo: Hucitec, 2000. 
O'CONNOR, J. History and nature. In: Natural causes: essays in ecological Marxism. New York: Guilford Press, 1998, p. 19-28.

OGBORN, M. Global lives: Britain and the world, 1550-1800. New York: Cambridge University Press, 2008.

OLIVEIRA, A.M.S.; QUEIROZ NETO, J.P. Depósitos tecnogênicos induzidos pela erosão acelerada no Planalto Ocidental Paulista. Boletim Paulista de Geografia v.73, p. 91-123, 1994.

OLIVEIRA, A.M.S.; BRANNSTROM, C.; NOLASCO, M; PELOGGIA, A.; PEIXOTO, M.N.O. \& COLTRINARI, L. Tecnógeno: registros da ação geológica do homem. In: SOUZA, C.R.G.; SUGUIO, K.; OLIVEIRA, A.M.S.; OLIVEIRA, P.E. (Org.), O Quarternário no Brasil. Ribeirão Preto: Holos Editora, 2005, p. 363-378.

OLIVEIRA, J.R.M. História ambiental no Brasil: o percurso historiográfico de Warren Dean. Tese (Doutorado). Assis-SP: Faculdade de Ciências e Letras/Universidade Estadual Paulista, 2013.

OLIVEIRA, R.R. 'Fruto da terra e do trabalho humano': paleoterritórios e diversidade da Mata Atlântica no Sudeste brasileiro. Revista de História Regional v.20, n.2, p. 277-299, 2015.

OLIVEIRA, R.R.; FRAGA, J.S. Metabolismo social de uma floresta e de uma cidade: paisagem, carvoeiros e invisibilidade social no Rio de Janeiro dos séculos XIX e XX. GEOPUC - Revista do Departamento de Geografia da PUC-Rio v.4, n.7, p. 1-18, 2011.

OLIVEIRA, R.R.; FRAGA, J.S.; BERCK, D.E. Uma floresta de vestígios: Metabolismo social e a atividade de carvoeiros nos séculos XIX e XX no Rio de Janeiro, RJ. INTERthesis v.8, n.2, p. 286-315, 2011.

OLIVEIRA, R.R.; WINIWARTER, V. Toiling in paradise: knowledge acquisition in the context of colonial agriculture in Brazil's Atlantic Forest. Environment and History v.16, n.4, p. 483508, 2010.

PÁDUA, J.A. Um sopro de destruição: Pensamento político e crítica ambiental no Brasil escravista, 1786-1888. Rio de Janeiro: Jorge Zahar, 2002.

A Mata Atlântica e a Floresta Amazônica na construção do território brasileiro: estabelecendo um marco de análise. Revista de História Regional v.20, n.2, p. 232-251, 2015.

PELOGGIA, A.U.G. Relíquias da destruição: registros geológicos da supressão da Mata Atlântica no Vale do Paraíba. In: CABRAL, D.C.; BUSTAMANTE, A.G. (Org.), Metamorfoses florestais: culturas, ecologias e as transformações históricas da Mata Atlântica. Curitiba: Prismas, no prelo.

PELOGGIA, A.U.G.; SILVA, E.C.; NUNES, J.O.R. Technogenic landforms: conceptual framework and application to geomorphologic mapping of artificial ground and landscape as transformed by human geologic action. Quaternary and Environmental Geosciences v.5, n.2, p. 67-81, 2014.

PEREIRA, E.M. Da proteção da natureza ao desenvolvimento sustentável: a defesa ambiental no Rio Grande do Sul. Tempos Históricos v.15. n.2, p. 117-153, 2011. . Cartas pela natureza: a correspondência entre José Lutzenberger e o almirante José Luiz 
Belart (1973-1979). Historia Ambiental Latinoamericana y Caribeña v.4, n.2, p. 288-310, 2015.

SANTOS, M. A natureza do espaço. Técnica e tempo, razão e emoção. São Paulo: Hucitec, 1996.

Por uma outra globalização: do pensamento único à consciência universal. São Paulo: Record, 2001.

VASCONCELOS, P.A. Salvador: transformações e permanências (1549-1999). Ilhéus: Editus, 2002.

WATKINS, C.; VOEKS, R. A Mata Transatlântica: afrodescendentes e transformação socioecológica no litoral da Bahia. In: CABRAL, D.C.; BUSTAMANTE, A.G. (Org.), Metamorfoses florestais: culturas, ecologias e as transformações históricas da Mata Atlântica. Curitiba: Prismas, no prelo.

WILLIAMS, M. Deforesting the Earth: From prehistory to global crisis. Chicago: University of Chicago Press, 2003. 